\title{
Biodegradability of Lactide-Caprolactone Macromonomers in Wastewater
}

\author{
Roderquita K. Moore,* Roland Gleisner, and Carl J. Houtman \\ A desire to develop biorenewable materials has led to lactide- \\ caprolactone copolymers being used in adhesive, medical, and \\ pharmaceutical products. Use of this alternative material may diminish \\ human impact on the environment and create products that are \\ biocompatible. One advantage of these materials compared with other \\ typical petroleum-based polymers is that they are easily degraded by \\ microorganisms. In this study, the biodegradation of representative \\ lactide-caprolactone macromonomers and an acrylic pressure sensitive \\ adhesive incorporating these macromonomers was followed by a \\ respirometric method using a consortium of microorganisms found in a \\ typical wastewater treatment facility. The weight loss data of lactide- \\ caprolactone macromonomers showed that the lowest molecular weight \\ macromonomers with a high percentage of lactide had the greatest weight \\ loss, which could have been caused by the greater number of ester \\ linkages. Proton nuclear magnetic resonance data showed that for lower \\ molecular weight copolymers, there was a preferential loss of \\ caprolactone. Promisingly, testing of the full acrylic adhesives showed that \\ they were easily degraded and thus provided a route to more \\ environmentally friendly adhesive products.
}

Keywords: Adhesives; Biodegradable; Lactide-caprolactone; Macromonomer; Wastewater

Contact information: USDA Forest Service, Forest Products Laboratory, One Gifford Pinchot Drive, Madison WI 53726; *Corresponding author: roderquita.k.moore@usda.gov

\section{INTRODUCTION}

The synthesis and physical properties of copolymers of acrylates with acrylateactivated lactide-caprolactone macromonomers have been previously reported ( $\mathrm{Pu}$ et al. 2012). Lactide-caprolactone macromonomers were chosen because they can be biocompatible (Teramoto et al. 2004; Sartoneva et al. 2012), engineered to exhibit a range of properties (Wei et al. 2009), and derived from renewable feedstock (Groot et al. 2010). Biodegradable materials from renewable feedstocks are desirable to minimize human's environmental footprint and decrease remediation costs.

Lactide and caprolactone polymers assist in the advancement of medical applications (Ma et al. 2012), i.e., joint replacements, drug delivery systems, and scaffolds for tissue engineering (Jeong et al. 2004).

Previous work demonstrated that lactide-caprolactone macromonomers exhibit properties that compare favorably with commercial pressure sensitive adhesives (PSAs). This polymer is the keystone in our effort to make PSAs have a more closed life cycle. Figure 1 shows the idealized steps in the life cycle of a PSA in a paper label application. As represented in the figure, the macromonomers can be synthesized from agricultural products, e.g., corn starch or lactose, and the emulsion is copolymerized with petrochemically derived acrylate monomers. After being synthesized, the polymer emulsion may be blended with tackifiers and surfactants to formulate a stable product that 
is coated onto siliconized liner paper and bonded to a face stock paper during converting. The laminate is then die-cut into labels, which are applied to envelopes. After their service life, these envelopes are then recycled at a paper mill. The PSA leaves the paper mill in a solid rejects stream or is passed to water treatment where it is biodegraded by microorganisms. Pu et al. 2012 showed the synthesis, conversion, and utilization of the PSA materials. The goal of the current effort is to determine the factors that control biodegradation, which would close the life cycle.

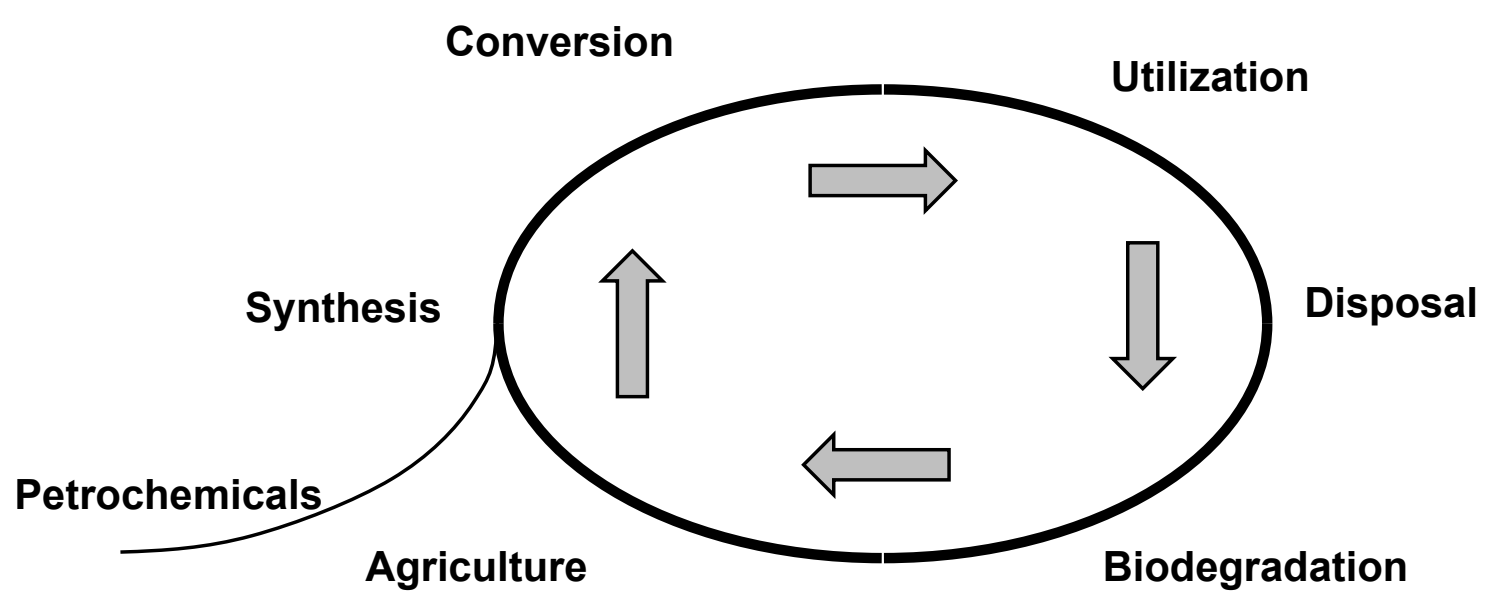

Fig. 1. Life cycle of PSA material for a paper label

Polymer biodegradation has been the subject of many studies and initiatives of standards-setting organizations. A widely practiced standard, OED 301 (1992), has been published by the Organisation for Economic Co-operation and Development (OECD). Reuschenbach et al. 2003 reviewed methods for respirometric monitoring of biodegradation using wastewater sludges. They found that systems based on pressure change with $\mathrm{CO}_{2}$ capture can provide reliable results. In the particular case of polyesters, such as lactide-caprolactone copolymers, many sludge microorganisms produce lipases (Nabarlatz et al. 2012), which are effective at cleaving ester linkages (Lenglet et al. 2009). Although there is some evidence that caprolactone polymers are more biodegradable than lactide-caprolactone copolymers ( $\mathrm{Li}$ et al. 2003), these materials should rapidly degrade when exposed to the consortium of microorganisms found in typical wastewater sludge because of the existence of esterase activity, which can break ester bonds in lactidecaprolactone copolymers.

The purpose of this study was to measure the biodegradation of lactidecaprolactone copolymers, with various lactide/caprolactone ratios, using microorganisms from municipal wastewater. A respirometric method was used, which measures the consumption of oxygen by microorganisms in wastewater treatment sludges. Although it is likely that all the macromonomers would be degraded by extended exposure, e.g., 28 days, to microorganisms as specified in many standards, 7 days of degradation was chosen better to observe differences between macromonomers of various compositions.

Furthermore, incomplete degradation allowed Raman and nuclear magnetic resonance (NMR) spectroscopy to be used to investigate the chemical changes during biodegradation. As a final test, the standard 28-day incubation was used to observe a fully polymerized PSA product. 


\section{EXPERIMENTAL}

\section{Materials}

Macromonomers and polymers were donated by Bioproducts and Biosystems Engineering, University of Minnesota (St. Paul, MN). The 2-hydroxyethyl methacrylate (HEMA), magnesium sulfate, calcium chloride, ferric chloride, potassium hydrogen phosphate, potassium dihydrogen phosphate, sodium hydroxide, glucose, and glutamic acid were all purchased from Sigma-Aldrich, Inc. (St. Louis, MO). Portex Sodasorb was purchased from Smith Medical, Inc. (Minneapolis, MN). Glass filter paper was purchased from Fisher Scientific (Fair Lawn, NJ), and wastewater sludge was donated by the Madison Metropolitan Sewer District treatment plant (Madison, WI).

\section{Methods}

Macromonomers and polymers were synthesized at the University of Minnesota as described previously ( $\mathrm{Pu}$ et al. 2012). The L-isomer of lactide was used for all these materials. Briefly, the macromonomers were produced by ring opening polymerization catalyzed with stannous octoate at $130{ }^{\circ} \mathrm{C}$. The macromonomers were terminated with a 2hydroxyethyl methacrylate (HEMA) group to facilitate copolymerization with other monomers to make an acrylate polymer. The acrylic polymer, which incorporated the macromonomers, was produced by mini-emulsion polymerization of the macromonomer, butyl acrylate, vinyl acetate, and methyl acrylic acid catalyzed by potassium peroxodisulfate at $80^{\circ} \mathrm{C}$.

\section{Glass Fiber Filter Paper Coupons}

The macromonomer and adhesive samples were introduced into the bottles by adsorbing them on glass fiber filter paper coupons. The macromonomers were dissolved in chloroform and added dropwise until the filter paper was completely saturated (approximately $50 \mathrm{mg}$ ). After the solvent evaporated under a fume hood, the coupon was reweighed to determine the amount of macromonomer added (approximately $14 \mathrm{mg}$ ). Four glass filter paper coupons were generated for each of the macromonomers listed in Table 1. Three coupons in each bottle were placed in the dilution water-inoculum mixture and incubated at $22{ }^{\circ} \mathrm{C}$ for 7 days. Eight bottles, each containing three different macromonomers, were placed on separate coupons, and two controls were monitored simultaneously.

The adhesives were added to the glass fiber as two separate samples: as an emulsion after synthesis and after it was dialyzed against water to remove the surfactant required for synthesis. For both samples, approximately $90 \mathrm{mg}$ of the adhesives were added. The three coupons were placed in the dilution water-inoculum mixture in the bottles and incubated at $22{ }^{\circ} \mathrm{C}$ for 28 days. Experiments of adhesive products were done. Twelve replicates of the adhesive samples were prepared on glass fiber coupons. Four bottles were prepared with three coupons in each bottle. Three of the bottles contained buffer and inoculum, and the fourth bottle contained buffer only. A total of ten bottles, eight bottles and two controls, were incubated for 28 days at $22{ }^{\circ} \mathrm{C}$.

After the required incubation period, the macromonomer or adhesive glass fiber coupons were removed from the bottles and washed three times in deionized water. No sludge material was visible on any of the coupons. The coupons were dried at $105{ }^{\circ} \mathrm{C}$ overnight before weighing them again to determine weight loss. 


\section{Biological Oxygen Demand Experiments}

Biological oxygen demand (BOD) experiments (Reuschenbach et al. 2003) were conducted in closed 300-mL screw-top bottles (Corning, Inc., Corning, NY) fitted with luer locks (Cole-Parmer, Inc., Vernon Hills, IL). An alkali carbon dioxide absorber (Portex Sodasorb (Smiths Medical, Inc., Minneapolis, MN), $1 \mathrm{~g}$ ) was suspended in the headspace of each bottle by gluing a 2-mL microcentrifuge tube (Corning, Inc.) to the bottle top. The microcentrifuge tube had 1-mm holes drilled in it to allow the air in the headspace to reach the absorbent. The pressure drop in the bottles was monitored by a pressure transducer (TruStability pressure sensor, Manufacturer no. HSCDANN030PAAA5 (Honeywell, Golden Valley, MN)). The pressure of ten bottles was monitored continuously by a computer acquisition system based on a National Instruments (Austin, TX) USB-6112 board and in-house software written in Visual Basic for Microsoft Excel.

Three mineral salts stock solutions were prepared by dissolving the following salts in one liter of deionized water: (1) magnesium sulfate $(22.5 \mathrm{~g})$, (2) calcium chloride (36.4 g) and ferric chloride $(0.25 \mathrm{~g})$, and (3) potassium hydrogen phosphate $(21.4 \mathrm{~g})$ and potassium dihydrogen phosphate $(24.9 \mathrm{~g})$, which was adjusted to $\mathrm{pH} 7.2$ with sodium hydroxide. One liter of positive control stock solution was prepared by dissolving glucose $(0.15 \mathrm{~g})$ and glutamic acid $(0.15 \mathrm{~g})$ in one liter of deionized water. The inoculum was prepared by collecting a sample of the primary sludge thickener accepts from the Madison Metropolitan Sewer District treatment plant. The sludge material was kept at room temperature $\left(25^{\circ} \mathrm{C}\right)$ and stored in a polypropylene bottle for at least 4 weeks before use. Fresh sludge has a high level of biological activity, and the difference between positive and negative control was not significant. The inoculum was prepared by taking $10 \mathrm{~g}$ of the sludge and diluting it with $90 \mathrm{~mL}$ of the phosphate buffer solution just before use.

To prepare samples for a test, dilution water was made by adding $1 \mathrm{~mL}$ of each of the three stock mineral solutions to $1 \mathrm{~L}$ of deionized water. The dilution water was saturated with air by bubbling air through it for $15 \mathrm{~min}$ using a diffuser. The typical sample bottle was prepared by placing $88 \mathrm{~mL}$ of the dilution water in the bottle and adding $12 \mathrm{~mL}$ of the diluted inoculum. For the positive control, $2 \mathrm{~mL}$ of the positive control stock solution and only $86 \mathrm{~mL}$ of dilution were added. For the buffer control, $100 \mathrm{~mL}$ of dilution water were added but no inoculum was added.

The BOD calculations were performed using the method described by Reuschenbach et al. (2003).

\section{Bruker MultiRam Spectrometer}

The FT-Raman spectra were obtained using a Bruker MultiRam spectrometer (Bruker Optics, Inc., Billerica, MA) equipped with a 1-W, 1064-nm Nd: YAG diode pumped laser. Spectra were acquired by directing the laser onto the macromonomercontaining glass fiber filter paper. The laser power for the sample excitation was $900 \mathrm{~mW}$. A total of 1024 scans were accumulated in double-sided forward-backward scanning mode. Principal component analysis was accomplished following a published method (Press et al. 1992) and implemented as a Microsoft Excel module.

\section{Bruker Advance DPX-250 Spectrometer}

Proton $\left({ }^{1} \mathrm{H}\right)$ NMR experiments were performed on a Bruker Advance DPX-250 spectrometer with a 5-mm QNP probe and using the standard pulse sequence with a 1second relaxation delay. The samples were extracted from the glass fiber filter paper with deuterated chloroform. 


\section{RESULTS AND DISCUSSION}

As part of the experimental design, a series of macromonomers were synthesized. As shown in Table 1, the number-average composition and molecular weight $\left(\mathrm{MW}_{\mathrm{n}}\right)$ of the macromonomers, as confirmed by proton NMR analysis, was varied to span a range of lactide (L)/caprolactone (C) ratios. The experimentally determined number-average molecular weight ranged from 1000 to $2700 \mathrm{~g} / \mathrm{mole}$.

Table 1. Composition of the Macromonomers

\begin{tabular}{|c|c|c|c|c|}
\hline Target & $\mathrm{L} \exp$ & $\mathrm{C} \exp$ & $\mathrm{MW}_{\mathrm{n}}(\mathrm{Da})$ & $\mathrm{L} / \mathrm{C} \%$ \\
\hline $\mathrm{L}_{20} \mathrm{C}_{4}$ & 21.6 & 4.1 & 2154 & $84 / 16$ \\
\hline $\mathrm{L}_{16} \mathrm{C}_{4}$ & 17.0 & 4.3 & 1843 & $80 / 20$ \\
\hline $\mathrm{L}_{10} \mathrm{C}_{4}$ & 11.2 & 4.6 & 1460 & $71 / 29$ \\
\hline $\mathrm{L}_{4} \mathrm{C}_{4}$ & 4.5 & 4.7 & 985 & $49 / 51$ \\
\hline $\mathrm{L}_{10} \mathrm{C}_{2}$ & 11.8 & 2.9 & 1316 & $80 / 20$ \\
\hline $\mathrm{L}_{10} \mathrm{C}_{8}$ & 10.7 & 8.9 & 1919 & $55 / 45$ \\
\hline $\mathrm{L}_{10} \mathrm{C}_{12}$ & 10.7 & 13.1 & 2400 & $45 / 55$ \\
\hline $\mathrm{L}_{10} \mathrm{C}_{16}$ & 10.0 & 16.0 & 2677 & $38 / 62$ \\
\hline
\end{tabular}

${ }^{*} \mathrm{~L}=$ lactide, $\mathrm{C}=$ caprolactone, $\mathrm{MW}_{\mathrm{n}}=$ number-average molecular weight, $\mathrm{L} / \mathrm{C} \%=$ exp. molar $\%$

These various macromonomers were exposed to the microorganisms found in municipal wastewater sludge. Although standard tests (OECD 301 1992) specify 28-day incubation periods, a 7-day incubation was chosen to avoid complete mineralization, because materials were needed for our subsequent analysis. Other studies using the 28-day incubation showed very high degradation $(>90 \%)$ of lactide-caprolactone copolymers ( $\mathrm{Li}$ et al. 2003).

The copolymers degradation is dependent upon the lactide/caprolactone ratios and the degradation environment. Kister et al. (2000) determined that when lactide was greater than $40 \%$ and caprolactone was less than 20\% (PLAxCLY $X \geq 40 \%$ and $Y<20 \%$ ), there was a preferential degradation of the amorphous parts of the polymer.

Decreases in degradation were observed for other $\mathrm{L} / \mathrm{C}$ compositions. The explanation for the decrease in degradation could be due to reduced susceptibility of the predominant iso-dyads (LL, or DD pairs) to hydrolysis. Note, the present experiments were conducted with only L-lactide.

Figure 2 shows the estimated BOD versus time of incubation at $22{ }^{\circ} \mathrm{C}$. All macromonomers were rapidly degrading. Even after only seven days, final BOD values represent approximately $10 \%$ to $30 \%$ of the total BOD available given the weight and composition of the macromonomers placed in the bottles.

FT-Raman spectra were obtained before and after exposure to microorganisms. Figure 3 shows the carbonyl region of spectra of the recovered $\mathrm{L}_{10} \mathrm{C}_{4}$ polymer after being exposed to the microorganisms for 3 and 10 days. The pure $\mathrm{L}_{10} \mathrm{C}_{4}$ is shown in the inset of Fig. 3. The spectra show that the vinyl group decreased significantly between day 3 and 10. The conclusion drawn from the FT-Raman spectra are also supported by the observation of the loss of the two downfield resonances assigned to the vinylic protons observed by the ${ }^{1} \mathrm{H}$ NMR spectra (not shown). The spectra from the NMR and Raman support the degradation in the vinyl groups less conclusive with respected to carbonyl groups. 


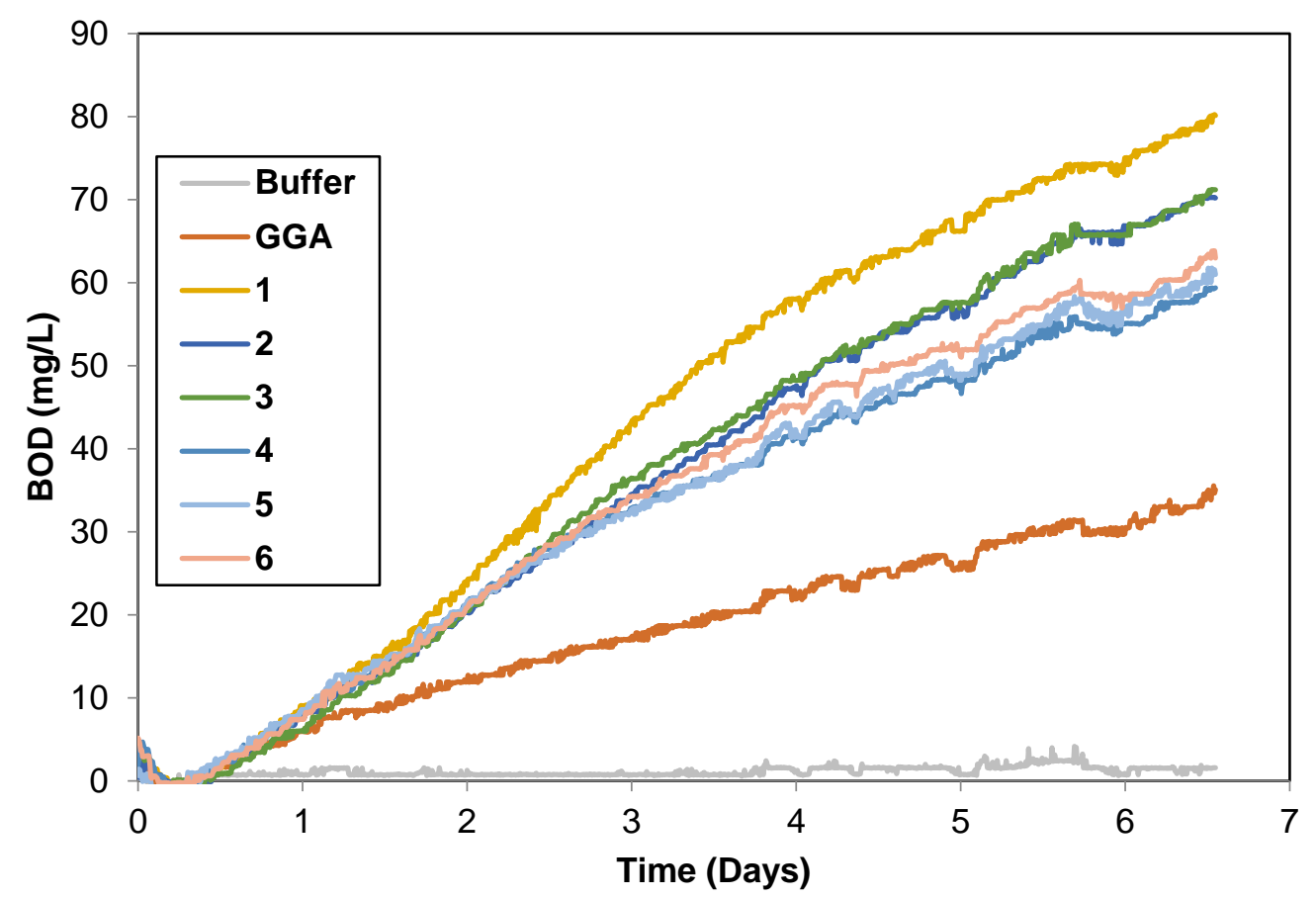

Fig. 2. Calculated BOD values for 8 bottles used in this study. Buffer represents data for the uninoculated buffer control, and GGA represents data for the glucose/glutamic acid positive control.

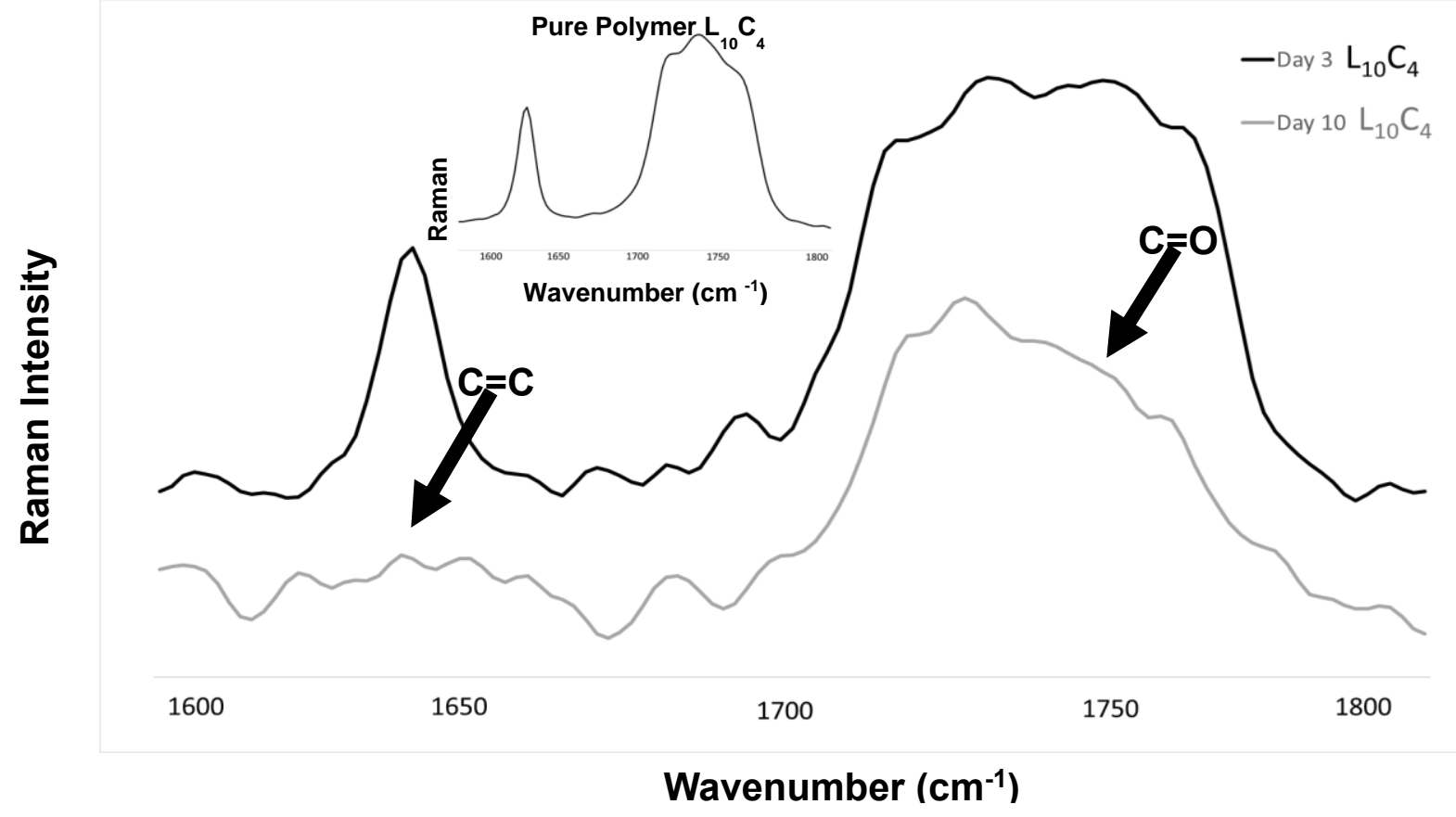

Fig. 3. Raman spectra of 3 and 10 days $\mathrm{L}_{10} \mathrm{C}_{4}$ macromonomer solution. carbonyl $(C=O)$ and vinyl $(\mathrm{C}=\mathrm{C})$ stretches regions are indicated. The inset shows the starting material.

To make general conclusions about the spectral changes, principal component analysis (PCA) was conducted on the whole data set. FT-Raman spectra were analyzed using PCA. One of the PCA components differentiated between before and after spectra. 


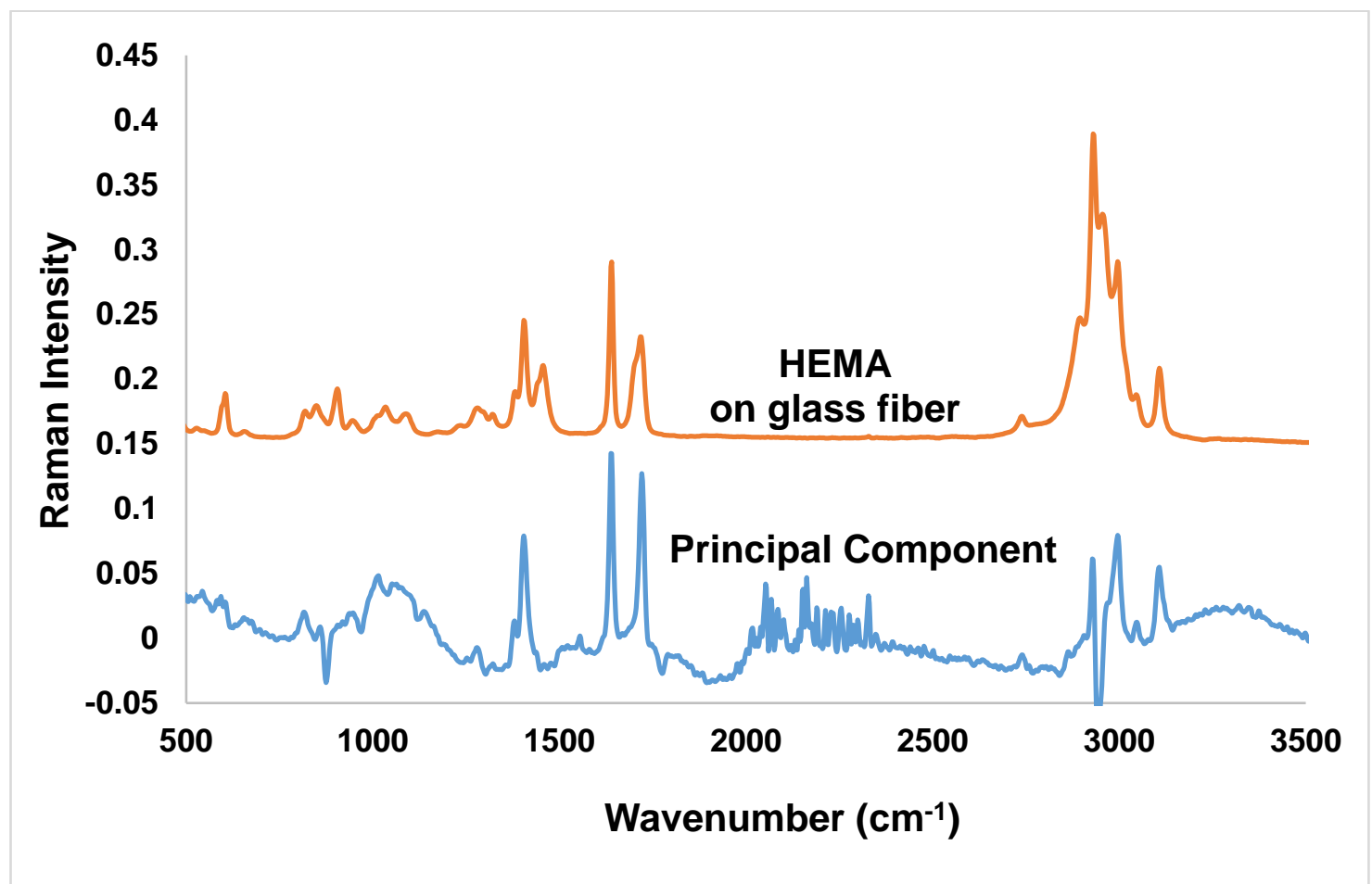

Fig. 4. Principal component vector corresponding to the dimension that differentiates before and after degradation Raman spectra. For comparison, the spectrum of HEMA absorbed on glass fiber is also shown.

Figure 4 shows the principal component and the spectrum of the HEMA starting material adsorbed on glass fiber. The peak assignments are $1400 \mathrm{~cm}^{-1}$ vinyl $\mathrm{C}-\mathrm{H}$ bend, $1640 \mathrm{~cm}^{-1} \mathrm{C}=\mathrm{C}$ stretch, $1720 \mathrm{~cm}^{-1} \mathrm{C}=\mathrm{O}$ stretch, $2900-3000 \mathrm{~cm}^{-1}$ methylene $\mathrm{C}-\mathrm{H}$ stretch, and $3100 \mathrm{~cm}^{-1}$ vinyl $\mathrm{C}-\mathrm{H}$ stretch. A positive peak in the principal component means that intensity was lost at these locations during degradation. The strong similarity between these spectra indicated that the HEMA group is rapidly removed by the microorganisms.

Although the Raman spectra indicated a loss of material after exposure, variance in the data did not allow firm conclusions. However, weighing the coupons before and after exposure to the microorganisms showed significant changes. The data are expressed as a percentage of the original mass and are shown in Fig. 5. The line on this figure indicates the expected weight loss if only the HEMA group is removed, as was indicated in the Raman spectra. In all cases, the data were statistically significantly above $(p<0.05)$ the HEMA line, confirming that caprolactone-lactide components were also removed during biodegradation.

Figure 5 also shows that lower molecular weight materials were removed more quickly than higher molecular weight materials. Furthermore, the $\mathrm{L}=10$ materials appear to have been more rapidly removed than the $\mathrm{C}=4$ materials. This could be due to more ester linkages available to be hydrolyzed by esterases (Hou 1993) of the inoculum, or the slightly higher water solubility of lactide fragments compared with caprolactone (Garkhal et al. 2007). 


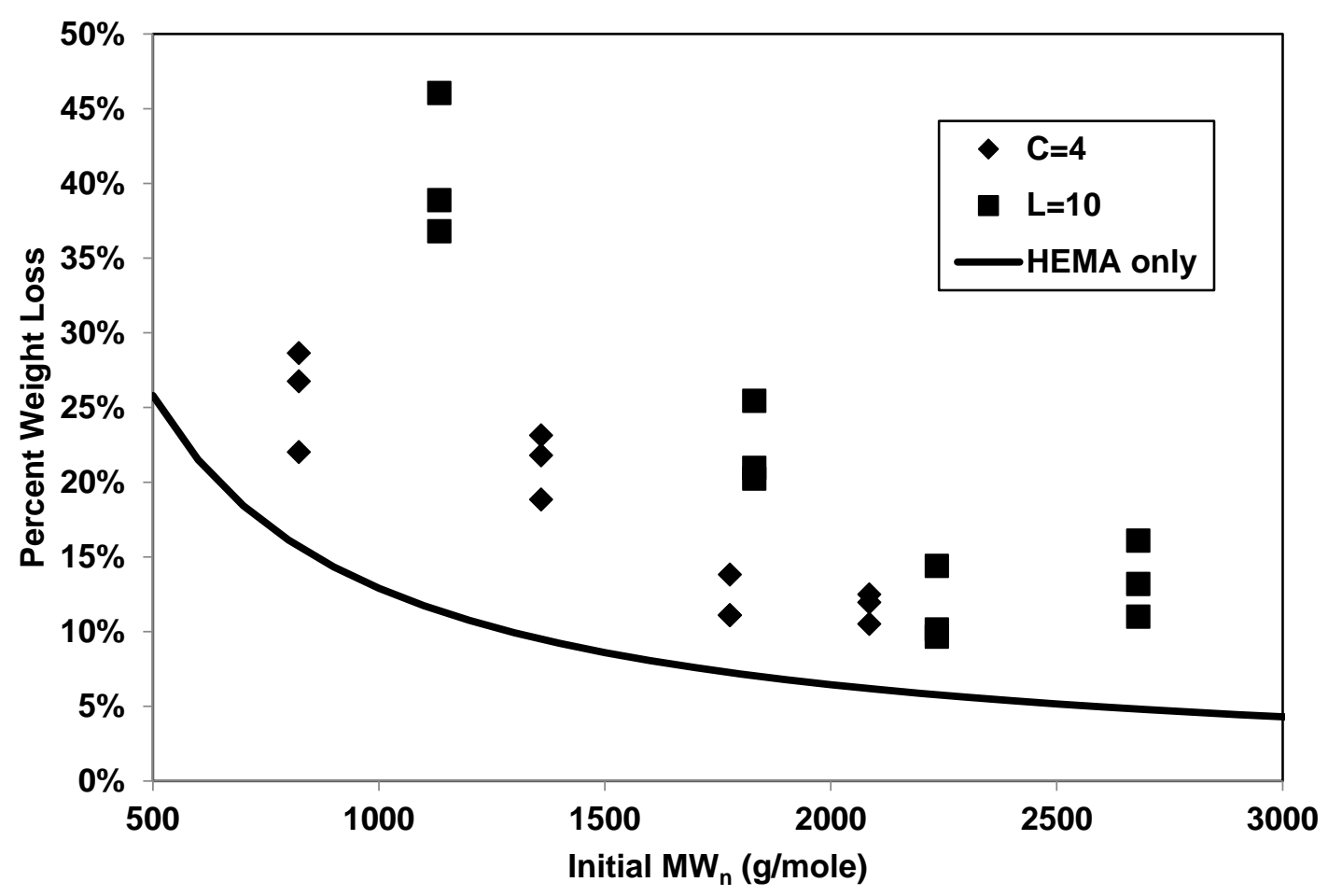

Fig. 5. Percent weight loss versus the number-average molecular weight of the initial macromonomer

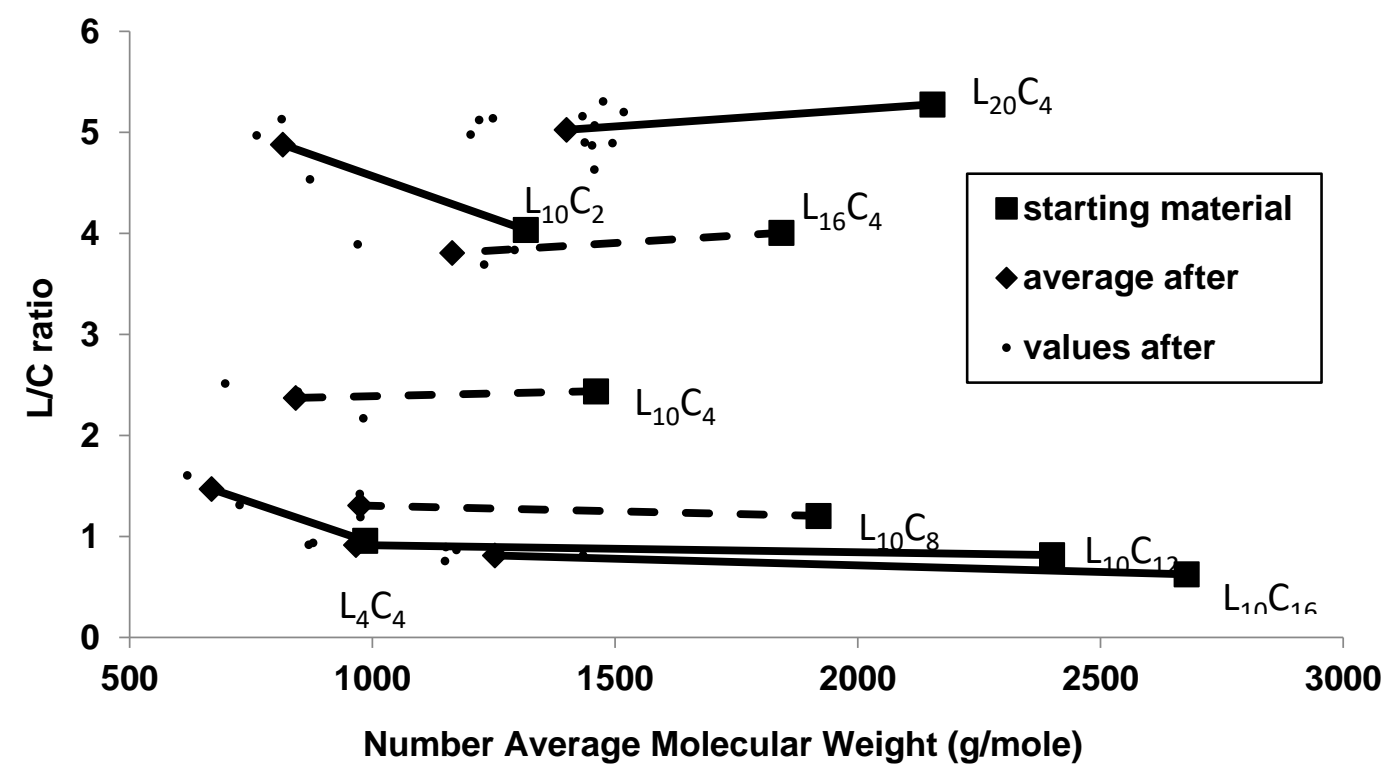

Fig. 6. L/C, is the number ratio, as determined by proton NMR and plotted versus the numberaverage molecular weight. Lines connect corresponding starting material data to afterdegradation data. Solid lines indicate a statistically significant difference in $L / C$ ratio $(p<0.05)$ between before and after degradation; dashed lines indicate that the difference was not significant.

The macromonomers were completely soluble in chloroform, thus it was possible to obtain high resolution ${ }^{1} \mathrm{H}$ NMR spectra. As described previously ( $\mathrm{Pu}$ et al. 2012), the number-averaged molecular weight and the lactide/caprolactone ratio (L/C ratio) can be 
calculated from the values of the peak integrations in the proton ${ }^{1} \mathrm{H}$ NMR spectra. As listed in Table 1, the molecular weights of the starting materials ranged between 1000 and 2700 g/mole. These data are also shown in Fig. 6 as the square symbols. Also shown in this figure are data for replicates of materials after exposure to the microorganisms. Although scatter in the starting material data was smaller than the symbols on this figure, the afterdegradation results had significant scatter, which can be attributed to the limited amount of material recovered after degradation. Also indicated by diamonds in Fig. 6 are the averages of the after-degradation data. The lines connect the starting material data to the corresponding after-degradation average data. In all cases, there appears to be a decrease in molecular weight. Because higher molecular weight materials are less soluble than lower molecular weight materials, this decrease probably indicates cleavage of ester linkages in the macromonomers.

The macromonomers $\mathrm{L}_{10} \mathrm{C}_{2}$ and $\mathrm{L}_{4} \mathrm{C}_{4}$ had the most degradation, $40 \mathrm{wt} \%$ and 26 $\mathrm{wt} \%$, respectively. The $\mathrm{L}_{4} \mathrm{C}_{4}$ was transparent and $\mathrm{L}_{10} \mathrm{C}_{2}$ was slightly opaque, suggesting that it may have been more crystalline or possibly underwent microphase separation. It has been previously observed that degradation of amorphous materials is faster than crystalline materials (Garkhal et al. 2007). The present results do not seem to show the same trend. Perhaps there are factors beyond crystallinity that control the degradation. For example, $\mathrm{L}_{10} \mathrm{C}_{2}$ has more available ester linkages than the $\mathrm{L}_{4} \mathrm{C}_{4}$, which may mean more sites for esterase action, or the two macromonomers have different solubilities in the culture system.

The L/C ratio data, shown in Fig. 6, were subjected to t-tests (Box et al. 1978) to determine if there was a statistically significant change in the ratio between before and after degradation. In Fig. 6, solid lines indicate significance $(\mathrm{p}<0.05)$ and dashed lines are not significant. The two lowest molecular weight macromonomers samples appear to show a preferential loss of caprolactone. The data presented here clearly show that the lactidecaprolactone macromonomers were rapidly degraded by the microorganisms in municipal wastewater.

In the final product, these macromonomers were combined with other acrylate monomers and emulsion polymerized to make high-molecular-weight polymers. During the emulsion polymerization, a surfactant is required. Typically, this surfactant remains in the final commercial product. For biodegradation testing, however, this surfactant could contribute to weight loss and oxygen consumption. The $\mathrm{L}_{10} \mathrm{C}_{4}$ macromonomer was used to synthesize an adhesive product. One portion of the resulting emulsion was directly applied to glass filter paper. Another portion was subjected to extended dialysis, which has been shown to remove the surfactant (Li et al. 1998). The surfactant-free adhesive was also applied to the glass filter papers.

Representative BOD curves for adhesive samples are shown in Fig. 7. The large spike in the data near day eight was related to disturbing the bottles to flush the headspace with fresh air when the oxygen consumption arrived at $90 \%$ of that initially available in the bottle. In all cases, the adhesives provided materials that the microorganisms could metabolize, well above the baseline metabolism of the inoculum-only control. Furthermore, at 28 days, the degradation of the polymers was continuing. Although the surfactant was expected to be preferentially removed compared with the adhesive (Li et al. 1998), there did not appear to be any difference between the samples that contained surfactant with those that did not in the BOD data. 


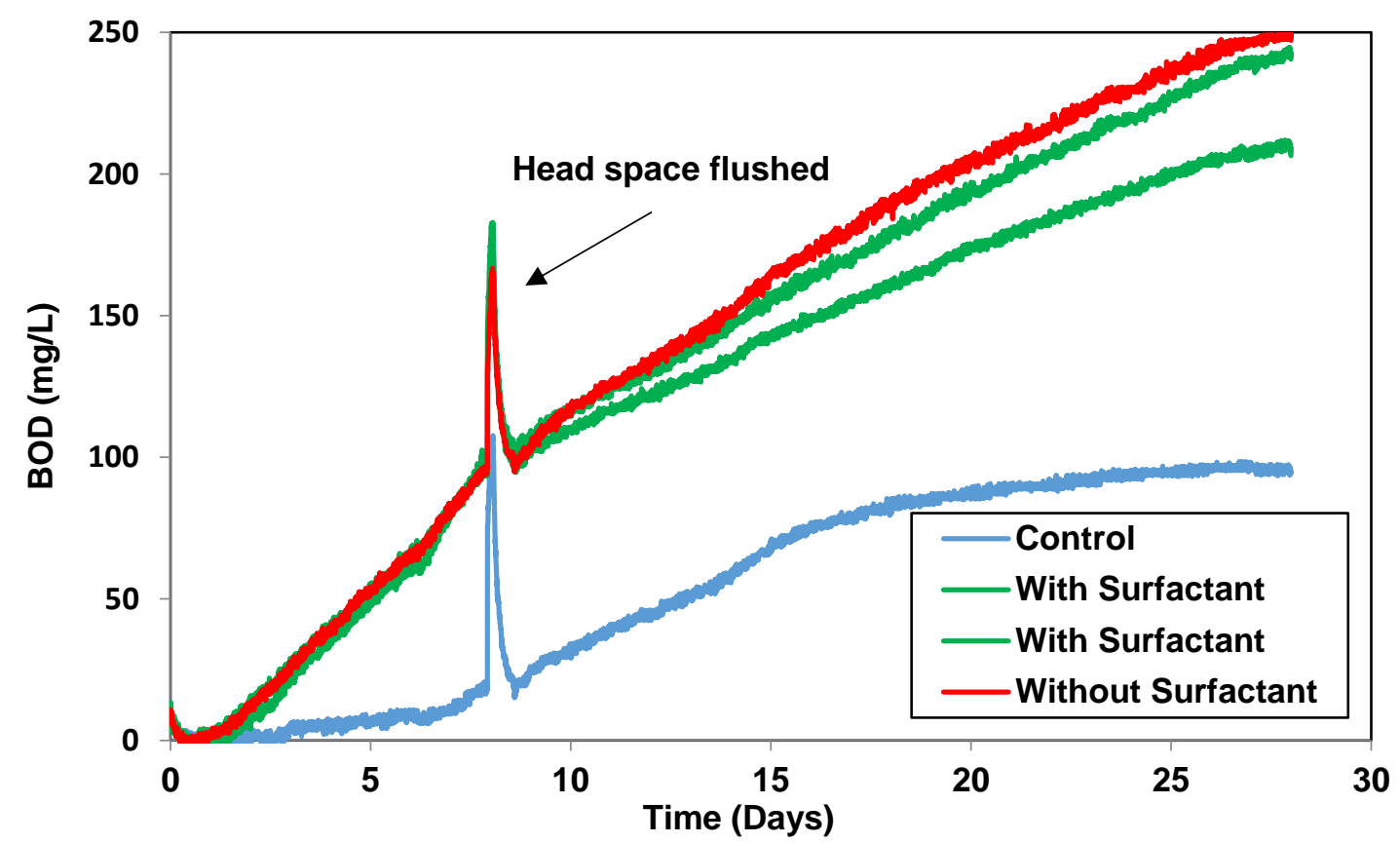

Fig. 7. Calculated $B O D$ values for adhesive products formulated with the $L_{10} C_{4}$ macromonomer. Control was inoculum and buffer only (selective samples).

Table 2. Weight Loss of Adhesives after 28 Days

\begin{tabular}{|c|c|c|c|}
\hline & & Average & $95 \% \mathrm{Cl}$ \\
\hline With Surfactant & Treatment & $15.8 \%$ & $1.4 \%$ \\
\hline Without Surfactant & Control & $11.9 \%$ & $1.1 \%$ \\
\hline & Treatment & $12.0 \%$ & $0.7 \%$ \\
\hline & Control & $10.6 \%$ & $0.9 \%$ \\
\hline
\end{tabular}

* $(n=9$ for the treatments and $n=3$ for the controls)

The weight loss of the coupons was also determined for each adhesive sample. Table 2 shows the results expressed as percent weight loss. Also shown are the 95\% confidence intervals for each of the average measurements. The only clear conclusion is that the "with surfactant" treatment showed higher weight loss than the corresponding control $(\mathrm{p}=0.006)$. The results for the samples without the surfactant are rather similar between the control and treatment.

\section{CONCLUSIONS}

1. Macromonomers of various compositions and molecular weights were tested for their biodegradability. Respirometry was used to monitor macromonomer and formulated adhesive degradation by the microorganisms in wastewater. In addition, Raman and NMR spectroscopy confirmed that some functional groups were degraded, and the molecular weights were reduced.

2. Among the eight macromonomers investigated, $\mathrm{L}_{10} \mathrm{C}_{4}$ and $\mathrm{L}_{4} \mathrm{C}_{4}$ lost the most weight after seven days, $40 \mathrm{wt} \%$ and $26 \mathrm{wt} \%$, respectively. In general, 
3. L10 macromonomers were more easily degraded.

4. A range of degradation rates have been observed. Our data suggest that morphology, crystalline vs. amorphous, molecular weight, L/C ratio, and water solubility may be important factors.

5. Lactide-caprolactone macromonomers are biodegradable and, when copolymerized with acrylate monomers, other results have shown to provide sufficient cohesive and adhesive strength to make a good commercial PSA. Thus, it is possible to make a more environmentally friendly adhesive product using these materials.

\section{ACKNOWLEDGEMENTS}

The authors thank Dylan Sturtevant, summer student, for assistance with preparation of samples, Steven J. Severtson and Drew Hague for helpful feedback and supplying materials (University of Minnesota), and Fred Matt (FPL) for HPLC (not shown). This research was funded by a grant from the United States Postal Service, Stamp Acquisition and Distribution.

\section{REFERENCES CITED}

Box, G., Hunter, W., and Hunter, J. (1978). Statistics for Experimenters: An Introduction to Design, Data Analysis, and Model Building, John Wiley \& Sons, Hoboken, NJ, USA.

Garkhal, K., Verma, S., Jonnalagadda, S., and Kumar, N. (2007). "Fast degradable poly(L-lactide-co-e-caprolactone) microspheres for tissue engineering: Synthesis, characterization, and degradation behavior," Journal of Polymer Science: Part A: Polymer Chemistry 45(13), 2755-2764. DOI: 10.1002/pola.22031

Groot, W., Krieken, J. V., Sliekersl, O., and Vos, S. D. (2010). "Production and purification of lactic acid and lactide," in: Poly(Lactic Acid) Synthesis, Structures, Properties, Processing, and Applications, R. Auras, L.-T. Lim, S.E.M. Selke, and H. Tsuji (eds.), John Wiley \& Sons, Inc., Hoboken, NJ, USA, pp. 1-18.

Hou, C. (1993). "Screening of microbial esterases for asymmetric hydrolysis of 2ethylhexyl butrate," Journal of Industrial Microbiology 11, 73-81.

Jeong, S., Kim, B., Lee, Y., Ihn, K., Kim, S., and Kim, Y. (2004). "Morphology of elastic poly(L-lactide-co-E-caprolactone) copolymers and in vitro and in vivo degradation behavior of their scaffolds," Biomacromolecules 5(4), 1303-1309. DOI: 10.1021/bm049921i

Kister, G., Cassanas, G., Bergounhon, M., and Hourau, M. (2000). "Structural characterization and hydrolytic degradation of solid copolymers of D,L-lactide-co- $\varepsilon$ caprolactone by Raman spectroscopy," Polymer 41(3), 925-932. DOI: 10.1016/S0032-3861(99)00223-2

Lenglet, S., Li, S., and Vert, M. (2009). "Lipase-catalysed degradation of copolymers prepared from caprolactone and DL-lactide," Polymer Degradation and Stability 94(4), 688-692. DOI: 10.1016/j.polymdegradstab.2008.12.023

Li, P., Xu, J. J., and Wu, C. (1998). "Surface functionalization of polymer latex particles. III. A convenient method of producing ultrafine poly(methylstyrene) latexes with 
aldehyde groups on the surface," Journal of Polymer Science Part A-Polymer Chemistry 36(12), 2103-2109. DOI: 10.1002/(SICI)10990518(19980915)36:12<2103::AID-POLA16>3.0.CO;2-A

Li, S., Liu, L., Garreau, H., and Vert, M. (2003). "Lipase-catalyzed biodegradation of poly(caprolactone) blended with various polylactide-based polymers," Biomacromolecules 4(2), 372-377. DOI: 10.1021/bm025748j

Ma, X., Wang, H., Jin, S., Wu, Y., and Liang, X. J. (2012). “Construction of paclitaxelloaded poly (2-hydroxyethyl methacrylate)-g-poly (lactide)-1,2-dipalmitoyl-snglycero-3-phosphoethanolamine copolymer nanoparticle delivery system and evaluation of its anticancer activity," International Journal of Nanomedicine 7, 13131328. DOI: $10.2147 / I J N . S 29371$

Nabarlatz, D., Stübea, F., Font, J., Fortuny, A., Fabregat, A., and Bengoaa, C. (2012). "Extraction and purification of hydrolytic enzymes from activated sludge," Resources, Conservation and Recycling 59, 9-13. DOI: 10.1016/j.resconrec.2011.06.017

OECD 301 (1992). "Ready biodegradability," Organisation for Economic Co-operation and Development, Paris, France. DOI: 10.1787/9789264070349-en

Press, W., Teukolsky, S., Vetterling, W., and Flannery, B. (1992). Numerical Recipes in C: The Art of Scientific Computing ( $2^{\text {nd }}$ ed.), Cambridge University Press, Cambridge, UK.

Pu, G., Dubay, M. R., Zhang, J., Severtson, S. J., and Houtman, C. J. (2012). "Polyacrylates with high biomass contents for pressure-sensitive adhesives prepared via mini-emulsion polymerization," Industrial \& Engineering Chemistry Research 51(37), 12145-12149. DOI: 10.1021/ie301492v

Reuschenbach, P., Pagga, U., and Strotmann, U. (2003). "A critical comparison of respirometric biodegradation tests based on OECD 301 and related test methods," Water Research 37(7), 1571-1582. DOI: 10.1016/S0043-1354(02)00528-6

Sartoneva, R., Haaparanta, A. M., Lahdes-Vasama, T., Mannerström, B., Kellomäki, M., Salomäki, M., Sándor, G., Seppänen, R., Miettinen, S., and Haimi, S. (2012). "Characterizing and optimizing poly-L-lactide-co- $\varepsilon$-caprolactone membranes for urothelial tissue engineering," Journal of The Royal Society Interface 9(77), 34443454. DOI: 10.1098/rsif.2012.0458

Teramoto, N., Kogure, H., Kimura, Y., and Shibata, M. (2004). "Thermal properties and biodegradability of the copolymers of L-lactide, caprolactone, and ethylene glycol oligomer with maleate units and their crosslinked products," Polymer 45(23), 79277933. DOI: 10.1016/j.polymer.2004.08.072

Wei, Z., Liu, L., Qu, C., and Qi, M. (2009). "Microstructure analysis and thermal properties of L-lactide/3-caprolactone copolymers obtained with magnesium octoate," Polymer 50(6), 1423-1429. DOI: 10.1016/j.polymer.2009.01.015

Article submitted: February 25, 2021; Peer review completed: April 11, 2021; Revised version received and accepted: April 17, 2021; Published: April 26, 2021. DOI: 10.15376/biores.16.2.4081-4092 